\title{
Safeguarding Deaf Children: a Multi-agency Focus on Actions for Change
}

DOI:

10.1080/09503153.2018.1450498

\section{Document Version}

Accepted author manuscript

Link to publication record in Manchester Research Explorer

\section{Citation for published version (APA):}

Wilson, S., Attrill, M., Critchley, T., Clements, D., Hornsby, J., Mullen, C., Miller, D., Redfern, P., Richardson, T., Young, A., \& Stow, L. (2018). Safeguarding Deaf Children: a Multi-agency Focus on Actions for Change. Practice, 163-186. https://doi.org/10.1080/09503153.2018.1450498

\section{Published in:}

Practice

\section{Citing this paper}

Please note that where the full-text provided on Manchester Research Explorer is the Author Accepted Manuscript or Proof version this may differ from the final Published version. If citing, it is advised that you check and use the publisher's definitive version.

\section{General rights}

Copyright and moral rights for the publications made accessible in the Research Explorer are retained by the authors and/or other copyright owners and it is a condition of accessing publications that users recognise and abide by the legal requirements associated with these rights.

\section{Takedown policy}

If you believe that this document breaches copyright please refer to the University of Manchester's Takedown Procedures [http://man.ac.uk/04Y6Bo] or contact uml.scholarlycommunications@manchester.ac.uk providing relevant details, so we can investigate your claim.

\section{OPEN ACCESS}


Safeguarding Deaf Children: a Multi-agency Focus on Actions for Change

Authors: "The Safeguarding Deaf Children Action Group (UK)"

Shirley Wilson. NSPCC National Services, $1^{\text {st }}$ Floor, Weston House, 42 Curtain Road, London. EC2A 3NH. Email: shirley.wilson@nspcc.org.uk Tel: 07786708620 (text only)

ORCiD: 0000-0003-3827-6734

Michelle Attrill. (formerly Suffolk County Council). Macmillan Family Support Worker, Family Support Team, Palliative Care, The Ipswich Hospital, Heath Road, Ipswich, Suffolk. IP4 5PD. Email: michelle.attrill@ipswichhospital.nhs.uk Tel: 01473704124

Tracey Critchley. Harrow College, Communication Support Unit, Harrow Weald campus, Brookshill, Harrow Weald, Middlesex. HA3 6RR. Email: tcritchley@ harrow.ac.uk. Tel: 02089096117

Daniel Clements. Royal Association of Deaf people, Century House South, Riverside Office Centre, Colchester, Essex. CO1 1RE. Email: daniel.clements@royaldeaf.org.uk Tel: 0845 6882527 (text phone)

Joanne Hornsby. Suffolk County Council, Inclusion Service, Health, Wellbeing and Children's Services, Suffolk County Council, West Suffolk house, Floor 2, Western Way, Bury St Edmunds. IP33 3YU. Email: joanne.hornsby@suffolk.gov.uk. Tel: 01473264717 Christopher Mullen. The National Deaf Children's Society, The National Deaf Children's Society, Second Floor, Vincent House, Quay Place, 92-93 Edward Place, Birmingham. B1 2RA. Email: ckmullen@ ndcs.org.uk Tel: 01212349825 
David Miller. NSPCC, Children's Services, Development and Delivery, $1^{\text {st }}$ Floor, Weston House, 42 Curtain Road, London. EC2A 3NH, Email: david.miller@nspcc.org.uk Tel: 0203 7729174

Paul Redfern. British Deaf Association, BDA England, College Business Centre, Uttoxeter New Road, Derby DE22 3WZ. Email: bdm.waleseng@bda.org.uk. Tel: Mobile: 07717 305739 (text/sms only)

Tim Richardson. National Deaf Child and Adolescent Mental Health Service, Leeds and York Partnership NHS Foundation Trust. Lime Trees, 31 Shipton Road, York, YO30 6RE. Email: trichardson1@ @ nhs.net Tel: 01904294231

Lynn Stow. Kent County Council, Team Manager, Sensory Services Team (Adults and Children), Adult Social Care and Health Directorate, Kroner House Eurogate Business Park, Ashford. TN24 8XU. Email: lynn.stow@kent.gov.uk Tel: 03000415444

*Alys Young. University of Manchester, Division of Nursing, Midwifery and Social Work, Jean McFarlane Building, Oxford Rd., Manchester. M13 9PL. Email: alys.young@manchester.ac.uk. Tel: 01613067747 ORCiD: 0000-0001-8551-5078

* Corresponding author. 


\begin{abstract}
This article concerns safeguarding deaf children and is written by a dedicated multidisciplinary consortium of national organisations, service providers and academics in the UK. Data are derived from 81 senior managers in social care, health, education, the police and voluntary sector organisations who attended a specialist conference concerning deaf children and safeguarding and who participated in three structured workshops. Thematic content analyses revealed their perspectives on risks and barriers to safeguarding deaf children at practice and organisational levels. An impact/effort matrix structure was used to elicit from participants a series of actions to improve practice and these were thematically organised. Findings are discussed in the context of the 2018 revisions to 'Working Together' in England, statutory reforms to PHSE in schools in England and recent NICE revised guidance on Child Maltreatment. Implications for practice are highlighted.
\end{abstract}




\section{Introduction}

This paper concerns deaf children and young people (henceforth referred to as deaf children) and how services (statutory and non-statutory) might more effectively identify and respond to their safeguarding needs. We use 'deaf' to refer to any degree of childhood deafness, from mild to profound, including sensorineural and permanent conductive deafness regardless of age of onset and the child's communication preferences which may encompass signed and/or spoken language (see below). It is also inclusive of deaf children who may have additional disabilities. With regard to adults/parents mentioned, some will be British Sign Language (BSL) users for whom to be deaf is a cultural identity that encompasses sign language use; when referring to this group we will use the convention of capitalisation 'Deaf' (Ladd 2003) or d/Deaf (Young and Temple 2014) when referring to all parents who are not hearing. We use 'safeguarding' to imply the full spectrum from promoting the physical, social, mental health and emotional wellbeing of children and young people with special educational needs or a disability (Children and Families Act 2014), through identification of risk and prevention of harm (HM Govt. 2017), to disclosure, identification and response to incidents of child maltreatment and abuse (NICE 2017).

In May 2016, a unique collaboration of specialist service partners ${ }^{1}$ led by the NSPCC (National Society for the Prevention of Cruelty to Children), delivered the first ever practitioner and research conference in the UK focussed solely on safeguarding deaf children (http://www.manchester.ac.uk/discover/news/nspcc-partnership-event-deaf-children-are-wekeeping-them-safe/). Hosted in collaboration with d/Deaf-sector organisations, statutory service providers and a specialist research group, this conference attracted over 100 people

\footnotetext{
${ }^{1}$ The consortium consists of the British Deaf Association (BDA), Harrow College, Kent County Council Children's Services, National Deaf Child and Adolescent Mental Health Services (NDCAMHS), National Deaf Children's Society (NDCS), National Society for the Prevention of Cruelty to Children (NSPCC), Royal Association for Deaf people (RAD), Suffolk County Council Children's Services, and University of Manchester (Social research with Deaf people group).
} 
drawn from the police, education, social work, private and voluntary sector, and health services in England. The vast majority of delegates were hearing. Specifically it was targeted at those with senior management level responsibilities.

In this article, we report delegates' perspectives on the most urgent practice-based and structural changes that require implementation in the context of their own localities effectively to safeguard deaf children. We publish these results in the context of the NICE revised guidelines 'Child Maltreatment: when to suspect child maltreatment in the under 18s' (NICE 2017) which although acknowledging pre-existing disability as a risk factor, did not address this as it lay outside of the scope of the guidance (p.6). Furthermore, the draft revision to Working Together, (due for publication in April 2018) includes in Appendix C no supplementary guidance with regard to disabled children or deaf children (HM Govt. 2017). Data are drawn from two workshop engagements that followed the conference plenary sessions. First, we provide a short background to current research and evidence-informed practice in this sector.

\section{Research background and practice contexts}

Meta-reviews support the conclusion that disabled children, including deaf children, are up to four times more vulnerable to abuse than their hearing peers (Kvam 2004; Miller and Brown 2014; NSPCC 2016a; Taylor, Stalker, and Stewart 2015) although the strength of the evidence is variable because of inconsistent sampling procedures, lack of clear demarcation of 'deaf' children from disabled children and the questionable applicability of evidence drawn from overseas to the UK service landscape. Nonetheless, key factors consistently identified associated with the vulnerability of deaf children to abuse include: the impact of barriers to communication and learning on deaf children's development of age-appropriate awareness, understanding and knowledge of sex and relationships; the isolation experienced through educational and other social structures, as well as having fewer communication 
partners, render children more likely targets for abusers; the inaccessibility of many sources of support and disclosure combined with a lack of fluent communication in the family (in whatever language or modality), reduce the opportunities to tell in the face of abuse. In addition, recent research with disabled and deaf adults who were abused as children, and the latest triennial analysis of Serious Case Reviews, has drawn attention to systems'- level failures in recognising abuse and the poor quality of investigation, response and subsequent support (Sidebottom et al. 2016). Cases of historical and systemic abuse are also emerging specifically concerning deaf children in the UK (BBC 2015). Threshold assessments, which are opportunities for good safeguarding practices, have been highlighted as points of particular concern with respect to disabled and deaf children. Ofsted's 2012 thematic review demonstrated the inappropriately high levels of tolerance of control and containment parenting behaviours which would be questionable in usual circumstances meaning that disabled children remain disproportionately managed as children in need when an escalation in assessment and intervention would be warranted.

This conclusion has been further reinforced by the recent SCR triennial review (Sidebottom et al. 2016) and an LSCB review of safeguarding practice with disabled children (NSPCC 2016b). The largest research study of local authority (England) practice with respect to deaf children (Young et al. 2010) demonstrated widespread failure to consider deaf children as children in need, even at the level of an initial assessment. Furthermore, it was not until the highest thresholds of evidence of harm had been reached that many services responded in the first place.

Fewer than 5\% of deaf children have deaf parents (Mitchell and Karchmer 2004). Deaf children growing up in hearing families are, from a developmental perspective, highly heterogeneous; whilst some remain monolingual spoken language users, many display differing degrees of bilingual communication in spoken/written language and a signed 
language such as British Sign Language (BSL), with the spoken not necessarily their strongest language (Hauser and Marschark 2008). BSL is an entirely visual, fully grammatical language, unrelated to spoken/written English (Sutton-Spence and Woll 1999). It is also very common for deaf children from hearing families, who might have been educated exclusively in spoken English, to transition to become BSL users in late childhood/early adulthood (Napier and Leeson 2016; Valentine and Skelton, 2007).

This complex developmental picture makes safeguarding practices particularly challenging. In part this is because the once vibrant specialist practitioner status of social workers with deaf people is all but extinct and the structural positioning of child protection expertise usually lies outside of specialist disability or deaf practices (Young, Hunt, and Smith 2008; Young et al., 2010). Consequently, it is far more usual for safeguarding professionals, whether social workers, police or others, to communicate indirectly through sign language interpreters in cases where a child or parent is a BSL user. Post-qualifying specialist training for sign language interpreters is not mandatory and many working in this sensitive field will have had no preparation in child protection. There is also limited evidence to suggest that awareness and understanding is low amongst many social work professionals of the impact of deafness on child development or that BSL use may be a cultural/linguistic facet of identity rather than an outward sign of hearing disability (Jones et al. 2016). This is of major concern because of Working Together's (HM Govt. 2017) emphasis on to the provisions and relevance of the Equality Act 2010 which "puts a responsibility on public authorities to have due regard to the need to eliminate discrimination and promote equality of opportunity. This applies to the process of identification of need and risk faced by the individual child and the process of assessment." (p.12 emphasis ours). Although there are pockets of specialist, and in some cases independent, d/Deaf social work 
provision and d/Deaf advocacy within safeguarding and child protection, these models are undocumented and rare.

\section{Methods}

\section{Overview of participant characteristics}

112 people attended the conference of whom 81 were delegates unconnected with its planning or presentation. They included principal and senior social workers, LADOs (Local Authority Designated Officer), children's services team leaders and heads of disability and sensory services, SEN (Special Educational Needs) leads, school principals and heads of hearing impairment teams, inspectors from within the Police with responsibility for child sexual exploitation and safeguarding, psychologists, paediatricians, speech and language therapists, mental health related staff and other specialist leads from within a range of voluntary sector and faith-based organisations. It is from this group of 81 , rather than the 112 present overall, from which the data were derived.

\section{Data collection}

The one day conference consisted of 6 formal presentations and two break out workshops. The presenters included practice professionals such as social workers and deaf mental health specialists, researchers in child protection and deafness, specialist safeguarding consultants as well as representatives from major $d$ /Deaf organisations. Conference delegates $(n=81)$ were divided into 5 workshop groups which were pre-chosen by the conference organisers (also the paper authors) in order to ensure that in each group there were a good mix of different professions and service contexts and that participants from the same geographical area would be dispersed. The workshops were each facilitated by two people (one Deaf and one hearing) and all of whom were experienced specialist practitioners. Each group was also allocated a notetaker. All facilitators had participated in a common briefing to maximise consistency and 
fidelity to workshop purpose was monitored by observers. The workshops followed plenary presentations on research and current practice.

In workshop 1, participants were asked: (i) to identify and discuss risks in relation to potential abuse faced by deaf children and (ii) key barriers to adequately safeguarding deaf children. Facilitators summarised the discussion in writing giving participants an opportunity to amend. Summary sheets from each group were posted in the main conference area for viewing by all participants.

In workshop 2, participants were asked to consider up to 5 specific actions that they felt might be implemented in their context that would improve safeguarding practice with respect to deaf children and their families. Participants were asked to consider actions that were in their power to take, given their role, and in reference to the context and service in which they were located. Each action was recorded on an adhesive note and participants invited to plot each one using an impact/effort matrix approach (ASQ 2010). In this approach, a four sector grid is derived from two axes; the horizontal runs from low to high effort and the vertical from low to high impact (see Figure 1). The resulting plotted actions from each group were shared with all participants on a conference wall for wider inspection. 
Figure 1. Impact/Effort Matrix Structure

Low Effort

High Impact

Analysis

Low Impact

Workshop 1

Summary sheets from each workshop were transcribed into an electronic form verbatim. One person from the authorial team carried out a thematic content analysis (Cresswell 2007), grouping together similar comments and observations under common categories. The draft thematic categories and their content were shared with the whole authorial group as a second stage check and minor amendments were made to classification within themes.

Workshop 2

Paper copies of the Impact/Effort Matrix analyses from each workshop were transcribed into an electronic form through placing the actions as written and plotted into each of the nine categories below (Table 1). One person carried out this process who was responsible for making a judgment about whether a given action should be considered 'medium' (effort or 
impact) depending on where it had been placed in the relevant sector of the matrix e.g. when someone placed their action on a border or toward the low end of the effort scale but not quite into the low effort sector etc. A sample of the judgements were checked by a second author independently. No further changes were required.

Table 1 - Categories into which the matrix actions were transcribed

\begin{tabular}{|l|l|}
\hline \multirow{4}{*}{ Low Impact } & Low Effort \\
\cline { 2 - 2 } Medium Impact & Medium Effort \\
\cline { 2 - 2 } & High Effort \\
\hline \multirow{4}{*}{ High Impact } & Low Effort \\
\cline { 2 - 2 } & High Effort \\
\hline & Medium Effort \\
\hline & High Effort \\
\hline
\end{tabular}

Where there were similar actions placed in the same location the number of times they were mentioned was not counted, only the nature of the action itself.

\section{Ethical considerations}

All participants were informed prior to and during the conference that their responses to the workshop activities would be collated and analysed and subsequently presented in an anonymised form which could include publication. During the conference, participants were reminded not to include in the written notes made and actions plotted the names of their 
organisations nor their geographical location, although they were free to do so on the day during discussion if they so wished. When reviewing the written information from the two workshop activities, the team further anonymised any potentially identifying features.

\section{Results}

\section{Workshop 1: risks to deaf children that might make them more vulnerable to abuse}

Themes are not presented in priority order. The brief explanation of each is derived from the participants' discussion and examples.

\section{Thresholds for service}

In general in children's services it is recognised that the threshold for eligibility for social work service provision is high in the face of prioritisation of scarce resources. However, with respect to deaf children, participants' main point was that professionals often cannot recognise that a deaf child meets the threshold in the first place. In part this was because of the scarcity of specialist social workers with knowledge about deaf children's development who can interact directly with deaf children and/or parents who might be BSL users. Consequently, they were less likely to be able to recognise risk or signs of neglect and abuse.

\section{New arrivals in the $U K$}

This theme concerned deaf children from other countries who have arrived in the UK with families often unaware of British law and systems. Three out of five groups specifically raised this issue. Its connection with safeguarding centred primarily on the preventative end of the safeguarding continuum. A particular focus was the risks involved in deaf children failing to achieve their linguistic and social potential because of barriers faced by their parents in accessing sources of support because of information being unavailable in parents' native languages. Uncertainty of citizenship status and poor socio-economic circumstances of many refugees and asylum seekers could mean that securing support and intervention for 
their deaf children was not prioritised in the face of much greater challenges faced by families.

\section{Lack of service connectivity}

Concern was expressed that poor connectivity and integration across health, education and social work services means that the needs of deaf children are regularly not identified and met. These were seen as social developmental needs, not just needs arising from failure to identify risk and abuse. Children who did not have an EHCP (Education, Health and Care Plan) were of particular concern because there was no formal driver for service connectivity.

\section{Personal and social development}

In participants' experience, many deaf children's personal and social development lags behind that of their hearing contemporaries making it harder for them to understand and identify appropriate and inappropriate relationships. It also makes them more vulnerable to sexual, physical and emotional abuse. Ineffective PHSE curricula and barriers to fluent communication and access to information in the family and amongst peers were seen as influential.

\section{Expectations of development hide safeguarding concerns}

Participants discussed how others' false expectations of what might be "typical" development for deaf children can obscure evidence of a safeguarding concern or a need to respond. For example, if professionals have low expectations of deaf children's linguistic and social development, they may not question why a deaf child's language, in any language, is severely delayed. This may be regarded as 'normal' rather than a result of deficits in the developmental environment. Acting-out or withdrawal behaviours may be regarded as usual for deaf children because they cannot express themselves well verbally when in fact they may be a result of abusive experiences. The isolation of deaf children in schools, without friends 
or peer groups may be normalised and explained as resulting from communication problems rather than addressed.

\section{Language barriers}

Language barriers were mentioned in relation to spoken foreign languages, communication more generally in spoken language and specifically in relation to BSL. There were two kinds of problem associated with potential risk: the ability of services to communicate with parents/families in their home language if it was other than English and the ability of parents to communicate well with their deaf children, including in BSL. However, the main emphasis from workshop participants was on the potentially poor communication between deaf children and their parents. Two groups commented on the idea that failure by parents adequately to communicate with their children (in any modality, whether spoken or signed) could constitute neglect. Developing good communication required effort and learning and some parents did not do this and/or services to enable them to do so were lacking. In addition, some people commented on the difficulties many deaf children have both with acquiring specific vocabulary they might need to tell someone about an abusive experience or in understanding the concepts behind some words in the first place, such as 'disclosure'.

\section{Peer abuse}

Although the majority focus on abuse with respect to deaf children concerns intra- and extrafamilial abuse that is adult to child, one group raised the issue of peer to peer abuse. They felt that this risk was generally not acknowledged despite some examples evident from within residential environments, such as special schools.

\section{Isolation}

Participants discussed the frequent isolation that deaf children and young people can experience in their everyday lives, in the home, school and local communities. They 
identified this as a safeguarding concern because of its potential association with the emotional and mental health difficulties they have seen deaf children and young people experience. The majority of deaf children are educated in mainstream schools, often without a deaf peer group and are the only deaf person in a family.

\section{Deaf parents' access to services}

This concern focussed on parents who were Deaf and who had either deaf or hearing children. It had several aspects. The first was concerns about the adequacy of parenting skills and knowledge. One group made the point that some Deaf parents had been "schooled" away from home and not actually experienced being parented within a family and therefore required support and learning in how to be parents. Even when this might be recognised, services to support parenting are largely inaccessible for Deaf parents both in the sense of availability of interpreters to enable access to e.g. parenting courses and in the sense of the resources and approach of many such courses not being very 'Deaf friendly'. Additionally, one group in particular discussed the problem of some Deaf parents' knowledge about what constituted 'abuse', largely as a result of their own experiences of poor parenting and also lifelong inadequate access to knowledge and information.

\section{Workshop 1: Barriers to adequately safeguarding deaf children}

Themes are not presented in priority order. The brief explanation of each is derived from the participants' discussion and examples.

\section{Deaf children not seen alone}

In child protection investigations it is important for a child to be able to be seen alone in order for the child to be able to 'speak freely', particularly in cases where close family members might be implicated in their abuse. Also direct communication between professional and 
child is seen as advantageous in understanding how the child might make sense of their experience through their own eyes, to build trust, rapport and provide support. However, participants suggested that the opportunities for a deaf child to be seen alone were often more restricted than is the case with hearing children because of communication requirements. For example, a family member might be asked to interpret for the child to the professional which although expedient, is inappropriate as impartial communication is required. An interpreter may be required for a professional to understand the child but this immediately breaks bonds of direct communication. In fact being able to make an assessment of what a child might need in terms of communication and language support was seen as not an easy judgment, particularly given the lack of knowledge of most professionals who work outside the specialist field.

\section{Preventative work}

Participants identified the lack of priority and resources for social developmental work with deaf children as a key limiting factor in effective safeguarding. There were few resources available to tackle, in a preventive way, the risks associated with isolation, lack of access to information and restricted opportunities social learning. Yet preventative work in these spheres could form the basis of a child developing their own awareness, knowledge and selfempowerment to combat abuse. The lack of multi-agency co-operation with respect to deaf children's and families' needs and the scarcity of specialist workers was thought to exacerbate this situation.

\section{Barriers to accessing universal services}

Participants recognised that whilst universal services are in theory accessible to deaf children and young people, in reality their accessibility was limited by services being unable routinely to meet deaf children's language and communication needs. Examples included staff not 
having the necessary signing skills, general lack of deaf awareness, poor acoustics in buildings and simply a lack of visible d/Deaf role models. Where services could be made accessible these might be at a significant distance away from parents of deaf children.

\section{Professional awareness}

It was generally agreed that the implications of deafness are not fully understood by professionals therefore the barriers to adequate safeguarding not recognised. For example, many agencies make provision for accessibility under the umbrella of 'disabled' users without the specific consideration of the problems faced by those with communication barriers beyond ESOL (English for Speakers of Other Languages).

\section{Interpreters}

Sign language Interpreters (SLIs) were mentioned in three groups. It was recognised that access to and availability of an interpreter was not straightforward and that there were associated issues, such as lack of clear responsibility for funding. These factors could mean that service providers might seek to avoid, not recognise or find it hard to commission SLIs when required. The lack of SLIs has implications across the whole safeguarding continuum whether in terms of assessment, identification of abuse, support of children and families, accessibility of services and specific actions associated with protection and legal rights connected with them.

\section{Deaf children's independent access to help and support}

Participants' drew attention to the importance for safeguarding of children's independent access to help and support and how this can very difficult for deaf children. It may be difficult for deaf children to find someone to 'tell' who is able to understand them (in signed or spoken language). Communication in the family may be restricted too. Help lines and other forms of remote support are commonly inaccessible either because of literacy (deaf 
children's written language development typically lags behind their age) or because they are dependent on spoken language use via telephone.

\section{Deaf/hearing mixed families}

Many participants discussed how deaf children growing up in hearing families could have safeguarding implications unless parents were adequately supported. For example, parents might be unaware that communication between themselves and their deaf children was poor because they might have low expectations of what is possible, accepting limited communication as typical for a deaf child when it is not an inevitable or unavoidable consequence of deafness. Parents may also not be aware of the impact of poor communication on a deaf child's socio-emotional development and world knowledge, both of which are components of keeping safe. However, it was also noted, that lack of resources to support families also contributes to problematic communication, for example lack of funded BSL classes available to parents.

\section{Workshop 2: Matrix Analysis Results}

A total of 140 different actions were recorded by participants although some acknowledged that any one action they envisaged might well lead to others as in some cases this was unknown territory as one participant noted:

“I will incorporate an analysis of the local authority's capacity/ response in relation to BSL \& deaf CYP \& report the findings to the LSCB. I have asked my office today if we already have knowledge of the number of social workers who sign \& their level of fluency - at the moment we do not have this information, so I will attempt to close this gap. At the moment this is an action surrounded by unknowns so I am not sure 
what the effort or impact will be - these answers may uncover more questions that affect impact/effort by how the answers play out \& what they reveal.”

The overall pattern of how the actions were appraised by participants in terms of impact and effort show a clear desire for high impact actions but not necessarily quick wins, with fewer actions identified with low or medium impact (see Table 2).

Table 2: Numbers of actions in the Impact/Effort Matrix

\begin{tabular}{|l|c|c|c|c|}
\hline & $\begin{array}{l}\text { Low } \\
\text { effort }\end{array}$ & $\begin{array}{l}\text { Medium } \\
\text { effort }\end{array}$ & $\begin{array}{l}\text { High } \\
\text { effort }\end{array}$ & TOTAL \\
\hline $\begin{array}{l}\text { Low } \\
\text { impact }\end{array}$ & 5 & 8 & 2 & $\mathbf{1 5}$ \\
\hline $\begin{array}{l}\text { Medium } \\
\text { impact }\end{array}$ & 11 & 30 & 6 & $\mathbf{4 7}$ \\
\hline $\begin{array}{l}\text { High } \\
\text { impact }\end{array}$ & 16 & 30 & 32 & $\mathbf{7 8}$ \\
\hline TOTAL & $\mathbf{3 2}$ & $\mathbf{6 8}$ & $\mathbf{4 0}$ & $\mathbf{1 4 0}$ \\
\hline
\end{tabular}

In broad terms, suggested actions fell into 6 categories. Some of these overlap but for purposes of clarity we separate them here.

Actions concerning improvements in personal and professional knowledge/understanding

The conference plenary presentations, supported by a comprehensive list of available resources, had succeeded in inspiring some participants to read more about the evidence supporting why deaf children might be more vulnerable to abuse and sensitised them to limited direct evidence available from deaf children. Prior to the conference, some delegates were unsure where to look for this information or how accessible the research evidence might 
be. Knowing what was out there, how to sign post others to it and where the research and professional expertise lay was identified as a key component in provoking better practice. Several participants committed themselves to revise some of their own work in light of increased knowledge about safeguarding deaf children, for example:

"I will review the LSCB safeguarding Deaf \& Disabled children training (which I deliver) to include information from today to highlight the issues/barriers/knowledge about safeguarding deaf children and young people".

For others, the individual professional challenge consisted of increasing their knowledge about available resources for deaf children and their families in their locality so as to better sign post to services; they reflected they had been unaware that they did not know about these until challenged through the experience of participation in the conference. For others the important learning had consisted in becoming aware of the limitations of their understanding about the complex relationship between deaf child development and potential abuse. As one delegate stated their action would be:

"Ensuring I look at a child's development/behaviour not in isolation i.e. are there developmental delays or behaviours not 'because they are deaf'"

\section{Actions concerning the dissemination of knowledge and information}

Many participants described the ways in which they would cascade the learning gained through the conference. The common thread expressed was to use the opportunity of the knowledge gained to improve awareness and practice. Therefore, participants extended the goal of cascading learning to one of establishing new training. In some cases, this was conceived of in single agency/team terms: 
“Develop/deliver revised 'deaf awareness' training packages for schools/colleges/ employers to identify safeguarding as key consideration. Include Deaf instructors in delivery as examples of 'real life deaf experience'.

In other cases participants emphasised the importance of multi-agency events because personnel who may work together do not necessarily train together and that is what would be required for safeguarding deaf children. Examples of concrete plans expressed included:

"I will arrange a multi-agency lunchtime seminar on safeguarding and the Deaf child to highlight issues for deaf children \& raise awareness - later in the year"

"Engage with LSCB regarding themes raised within conferences, especially social workers \& communication. Seek some collaborative working to upskill professionals" The readiness with which so many were able to form a specific plan about what they would do to promote awareness, understanding, knowledge and change in their own localities is perhaps, in part, a result of the conference having deliberately targeted senior managers.

\section{Actions connected with better evidence, data gathering, audit and review}

For some delegates the experience of the conference had left them with a strong awareness of how little they actually knew about deaf children in their locality contexts, whether in terms of number, service use or unmet need. Creating reliable data was seen as a priority to assist with service planning and improvement. Given the seniority of participants their commitment to this goal was a strong message for action. For example:

"Gather data in respect of CYP - Deaf numbers. What services are there in locality? Linking up via commissioning services.”

For others, the questions raised were ones of quality and whether local procedures were adequate whether in terms of preventative services available to support deaf children's well being, in spotting safeguarding concerns and responding appropriately, in developing and 
implementing appropriate support plans for deaf children and their families where required, as well as monitoring those in practice. In these cases, participants left with plans to implement audits as the basis for considerations of better practice. For example:

"Scoping exercise to see what gaps there are in my service \& raise outcome with leadership. Goal - Ensure all deaf children are accessing services \& or assessments according to need."

Actions designed to improve the working of a specific part of the multi-agency safeguarding system

Many participants highlighted actions within the broader multi-agency safeguarding systems that in their view were not adequately responding to deaf children or which could be enhanced to the benefit of deaf children. Some participants focussed on the absence or lack of clarity about a pathway for deaf children. This might arise because of current structures subsuming deaf children within disabled children's systems or because there was no all-age sensory pathway. Consequently, there were few opportunities or structures to enable cross agency collaboration specifically with respect to deaf children's needs. Participants identified important first steps:

"Develop working policies with social care to develop liaison between specialist sensory team (education) and social workers to enhance joint working/information sharing"

"Set up multi-agency working group"

For others who felt confident that their current structures adequately met deaf children's specialist needs, nonetheless there was commitment to test out that assumption.

"Scope if CP for deaf children [is being] undertaken by the Complex and Additional needs social care team. We hold the communication specialisms." 
"Meet with the Managers of the Disability Team which encompasses Deaf children \& look at what services are available and to ensure that services [are] accessible to Deaf children"

A few delegates had started thinking about unintended consequences that might arise from the ways in which generic structures designed to safeguard children could abrogate their responsibility to professional 'specialists', relying too heavily on them and failing therefore to carry out their duty.

"For safeguarding board to take responsibility for deaf children and not to defer to specialist practitioners to be strategic and operational"

Other actions pointed to the full integration of deaf child safeguarding issues into broader local safeguarding plans, guidance to professionals and associated training:

"I will include the awareness of the lived experience of deaf CYP in the LSCB's current work in capturing the voice of the child."

"Remind professionals to communicate their analysis/ impact on the child of communication/ language being 'denied' through neglect'

Actions associated specifically with communication and language.

Information and discussion at the conference had led many participants to consider whether and how their services might be failing in their equality duty on grounds of language. For example:

"Ways to report. Police line user friendly to Deaf children \& Adults. Text facility, Publicity \& Accessibility"

Some focussed on how to improve direct practice with deaf children: 
"For child to be seen first and 'deafness' as an assessed communication need to be part of all"

"Ensure that appropriate Interpreters are provided through all assessment processes"

Others expressed more personal reflections prompted by the bilingual (English and BSL) nature of the conference and the mixture of $\mathrm{d} /$ Deaf and hearing delegates and presenters. For some this was their first experience of this kind of linguistic/communicative environment and it had a personal impact:

“Look into learning some basic BSL. I felt 'disabled' that I couldn’t even communicate with deaf delegates in 'pidgen BSL' - I really understood their experience due to this reversal of experience!"

\section{Actions associated specifically with the deaf child}

Many of these actions concerned equipping deaf children and young people with better opportunities to learn about personal development, relationships and health, to become more aware of potential dangers, develop knowledge about what is abuse and provide means for how to report it.

“Increase focus in sensory support team on PSHE - improving deaf children's understanding of how to stay safe \& encouraging disclosure"

Some actions were more focussed on reducing the social isolation that might be experienced by deaf children now that delegates had become more aware of the link between such isolation and potential vulnerability:

"Consider how as a school we would meet the needs of deaf children... Developing the buddying scheme to be inclusive" 


\section{Discussion}

The findings have focussed attention on 4 key issues. We discuss each in turn with reference to evidence and policy and guidance.

\section{It is not about 'not hearing' it is about language and communication}

Across the whole safeguarding spectrum, whether in terms of the child's acquisition of knowledge and strategies to keep safe, identification by others of safeguarding concerns, opportunities for disclosure, child protection planning or formal responses to abuse, the key axis of vulnerability is language and communication. By this we do not just mean the challenges that many deaf children face in the development of age appropriate language and associated cognitive and social development (Marschark and Hauser 2008; Marschark and Spencer 2010), we also mean the language and communication limitations of professionals. Our data have demonstrated the clear need for professionals and service providers to become more aware of the limitations of their own knowledge and skills in the face of communicating with deaf children or indeed with parents who might be d/Deaf. This encompasses simple things such as being aware that how a deaf child communicates is not necessarily a good guide to the extent of what they can understand in the same language or communication medium. The same is true of deaf adults (Young and Hunt, 2011). It also encompasses more complex issues such as how and why a deaf child's reduced access to the wider communicative environment may result in gaps in a range of social and relational knowledge (Antia and Kreimeyer, 2015). This makes safeguarding interventions more challenging because the expected age-appropriate 'fund of knowledge' (Pollard and Barrnett, 2009) on which to build might be missing. Although some recent research (Jones et al. 2016; Taylor et al. 2015), as well as LSCBs acting on their responsibilities under the Equality Act 2010 (NSPCC 2016b), has resulted in a greater general awareness of the need for sign language interpreting provision within safeguarding and child protection procedures, the provision of 
an interpreter is only one small aspect of this complex picture (see below). Although NICE guidelines draw attention to making adjustments for factors that might make it more difficult for parents to access support, and disability is listed as one of those, there are no detailed guidelines on how to act on this (NICE 2018b, 5).

\section{The challenges to professionals' skills, knowledge and understanding}

Social workers in particular, but also education, police and health professionals, rely a great deal on their child protection prior experience, as well as their understanding of child development, to make sense of and form judgements about risk and the safeguarding needs of children. The NICE (2018) Early Help for Child Abuse and Neglect Pathway states:

"Commissioners and managers should ensure that all practitioners working at the early help stage:

- have an understanding of typical and atypical child development

- are able to tailor interventions to the needs of the child or young person, parents and carers including any disability or learning disability" (NICE 2018,

5)

As our data have highlighted, without specialist understanding of deaf children's trajectories of normal development and what are reasonable expectations of parenting, learning and social relations, professionals may be hard pressed to recognise when a deaf child is in need, when a family might benefit from a supportive intervention or when a deaf child is at risk or displaying signs of abuse. The presence of a sign language interpreter to assist communication with a deaf child who might sign does not solve this fundamental professional knowledge gap and is largely irrelevant in the case of children who are not sign language users. Collaboration with specialists might. These might include specialist social workers with deaf children and families, d/Deaf advocates, teachers of the deaf or specialists 
within some of the agencies who are co-authors of this paper. Yet prior research has highlighted how rare it is for social workers in particular to co-work child protection cases with d/Deaf-related specialist workers (Jones et al. 2016; Young et al. 2010).

In those situations where interpreters are used, old models of the role of the interpreter often predominate. For example they are seen as an impartial conduit for the transmission of information between languages and nothing else. Yet new models of interpreting are emerging with sign language interpreters being seen as practice professionals within a team approach (Dean and Pollard 2013; Napier and Leeson 2016). In this role, they are able to contribute their cross-cultural understanding and expertise directly with professional colleagues; for example during child and family assessments. In the UK, this approach is currently being used in specialist child and adolescent mental health practice with deaf children but not, as far as the authors are aware, in social work services involving deaf children or $\mathrm{d} /$ Deaf parents.

There are few practice resources available to assist safeguarding practitioners to increase their knowledge, understanding and practice skills in relation to deaf children. For example, the NICE (2018c) pathway on the recognition of child abuse and neglect barely mentions the implications of disability. One of the benefits noted by delegates at the conference was becoming aware of specialist resources and where to go to access expertise and support. These resources included, guidelines for LSCBs in their work with deaf children and with families where a parent may be deaf (Young, Hunt, and Stow 2010); a short blog aimed at social workers who are co-working with sign language interpreters (NSPCC 2017); the NSPCC specialist deaf and disability consultant service; the NDCS advice service for social work professionals who encounter deaf children in their work; the dedicated deaf child and adolescent mental health service in NHS England; as well as some of the research cited in this article. 


\section{Systemic level changes}

It is noteworthy that amongst the challenges recognised by participants, and which formed the focus of many commitments to action, were those at a systemic level within organisations. The conference had a strong effect in two sectors: (a) the requirement to carry out audit and implement quality reviews to understand the extent to which services were cognisant of and responded to safeguarding issues in a proactive way; (b) the need for training and education. These were seen as relatively easy actions to set in motion. It is testimony to the management level engagement with the conference that actions were targeted which align with the systemic approach emphasis of the recent review of SCRs (Sidebottom et al. 2016) and the tenor of the draft revisions and update of Working Together (HM Govt, 2017).

\section{Safeguarding materials and preventative resources for deaf children}

The effective engagement of deaf children with PSHE curricula is a key concern, particularly in light of recent government announcement that it will become a compulsory subject in primary schools with full implementation of the requirement by September 2019 (DfE 2017). The challenges in educational environments were well recognised amongst participants where there was a thirst for appropriate guidance and good resources. Amongst parents and families as well, the opportunities to involve deaf children in meaningful discussions and learning about how to stay safe have been hampered by a dearth of resources. Recently the NSPCC's successful 'Let's Talk Pants' initiative (NSPCC, undated) has been extended with the development of materials and films aimed specifically at deaf children and young people (NSPCC 2017b). The bespoke approach ensures that the knowledge needs and deaf children's preferred means of engaging with new information are at the heart of the development, which is not always the case when materials and resources aimed at children are 'adapted' or 'translated' for deaf children's use. Linguistic accessibility is only one 
aspect of knowledge acquisition (see for example, Young et al. 2016). 2017 has also seen the launch of the first Childline service that a deaf child who signs can contact and use autonomously because of the use of remote sign language interpreting services built in to its access and response (Childline, 2017). Childline's 'Deaf Zone' web site also contains lots of information for deaf children about many aspects of safeguarding accessible in a variety of media and languages.

\section{Conclusion}

Our vision is one of parity of safeguarding for deaf children with all children, whether in terms of equipping and empowering children themselves, supporting parents and families, or in terms of professional vigilance and service response. Those who participated in the conference have taken important steps toward this vision in their learning about risks and barriers to effective safeguarding and in their commitment to responding with tangible actions.

The key findings point to the importance of understanding and addressing safeguarding deaf children in terms of the challenges of ensuring linguistic access and intelligibility, not in terms of hearing and disability; the need for systemic level examination and change in order to prevent deaf children falling between the cracks of systems that seem to include them but in reality fail to identify or address their uniquely different requirements; the urgent need to upskill otherwise competent and experienced safeguarding professionals to practice well with deaf children; and the importance of providing more bespoke resources to better safeguard deaf children and enhance professional practice.

The UK Safeguarding Deaf Children Action Group who has come out of the conference initiative and has co-written this paper, is unique in the field and we will continue to campaign for better evidence and best practice in this field. 


\section{References}

Antia, S.D., and K.H. Kreimeyer. 2015. Social Competence of Deaf and Hard of Hearing

Children. New York: Oxford University Press.

ASQ. 2010. http://asq.org/healthcare-use/why-quality/impact-effort.html

BBC. 2015. Victims of historic sex abuse at deaf school speak about their ordeal.

http://www.bbc.co.uk/news/disability-34639080

Childline. 2017. Deaf Zone. https://www.childline.org.uk/info-advice/bullying-abusesafety/deafzone/

Creswell, J. 2007. Qualitative Inquiry \& Research Design: Choosing Among Five Approaches. Thousand Oaks, CA: Sage Publications, Inc.

Dean, R. K. and R. Q. Pollard. 2013. The demand control schema: Interpreting as a practice profession. North Charleston, SC: CreateSpace.

DfE. 2017. Policy statement: relationships education, relationships and sex education, and personal, social, health and economic education. https://www.gov.uk/government/publications/relationships-education-rse-and-pshe Freel, B. L., M. D. Clark, M. L. Anderson, G. L. Gilbert, M. M. Musyoka, and P. C. Hauser. 2011. 'Deaf Individuals' Bilingual Abilities: American Sign Language Proficiency, Reading Skills, and Family Characteristics". Psychology 2 (1):18-23.

Hauser, P. C., and M. Marschark. 2008. "What we know and what we don't know about cognition and deaf learners". In Deaf Cognition. Foundations and Outcomes, edited by M. Marschark and P. C. Hauser, 439-455. New York, NY., Oxford University Press.

HM Government. 2014. The Children and Families Act.

http://www.legislation.gov.uk/ukpga/2014/6/part/3 
HM Government. 2017. Working Together to Safeguard Children. A guide to interagency working to safeguard and promote the welfare of Children. April 2018.

https://consult.education.gov.uk/child-protection-safeguarding-and-family-law/workingtogether-to-safeguard-children-revisions-t/

Jones, C., K. Stalker, A. Franklin, D. Fry, A. Cameron, and J. Taylor. 2016. "Enablers of help-seeking for deaf and disabled children following abuse and barriers to protection: a qualitative study”. Child and Family Social Work. doi:10.1111/cfs.12293

Kvam, M.H. 2004. "Sexual abuse of deaf children. A retrospective analysis of the prevalence and characteristics of childhood sexual abuse among deaf adults in Norway". Child Abuse and Neglect 28 (3).

Mitchell, R. E. and M. A. Karchmer. 2004. "Chasing the mythical ten percent: parental hearing status of deaf and hard of hearing students in the United States”. Sign Language Studies (4): 231-244.

Ladd, P. 2003. Understanding Deaf Culture: In Search of Deafhood. Clevedon: Multilingual Matters.

Marschark, M., and P. Spencer. 2010. Evidence-Based Practice in Educating Deaf and Hard of Hearing Students. New York: Oxford University Press.

Napier, J., and L. Leeson. 2016. Sign Language in Action. London: Palgrave.

NICE. 2017. Child Maltreatment: When to Suspect Maltreatment in Under 18s (first published, 2009, revised 2017). https://www.nice.org.uk/guidance/cg89/chapter/1-Guidance NICE. 2018. Early help for child abuse and neglect. https://pathways.nice.org.uk/pathways/child-abuse-andneglect\#path=view\%3A/pathways/child-abuse-and-neglect/early-help-for-child-abuse-andneglect.xml\&content=view-node\%3Anodes-staff-competencies 
NICE. 2018b. Child abuse and neglect overview.

https://pathways.nice.org.uk/pathways/child-abuse-and-neglect

NICE. 2018c. Recognising child abuse and neglect.

https://pathways.nice.org.uk/pathways/child-abuse-and-

neglect\#path=view\%3A/pathways/child-abuse-and-neglect/recognising-child-abuse-and$\underline{\text { neglect } . x m l \& c o n t e n t=v i e w-i n d e x}$

Miller, D., and J. Brown. 2014. We Have the Right to Be Safe': Protecting Disabled

Children from Abuse. London: NSPCC. https://www.nspcc.org.uk/services-and-

resources/research-and-resources/2014/right-to-be-safe/

NSPCC. 2016a. Deaf and Disabled Children: Learning from Case Reviews. London:

NSPCC. https://www.nspcc.org.uk/preventing-abuse/child-protection-system/case-

reviews/learning/deaf-disabled-children/

NSPCC. 2016b. Safeguarding Disabled Children in England: How LSCBs are Delivering Against Ofsted Requirements to Protect Disabled Children.

https://www.nspcc.org.uk/globalassets/documents/research-reports/safeguarding-disabledchildren-england.pdf

NSPCC. 2017a. Helping Social Work Practitioners Communicate with Deaf Children. https://www.nspcc.org.uk/services-and-resources/impact-evidence-evaluation-childprotection/impact-and-evidence-insights/helping-social-work-practitioners-communicatewith-deaf-children/

NSPCC. 2017b. Learn the Underwear Rule.

https://www.youtube.com/watch?v=lvD74L86Mr8\&feature=youtu.be

NSPCC. undated. Let's Talk Pants. https://www.nspcc.org.uk/preventing-abuse/keepingchildren-safe/underwear-rule/ 
Ofsted. 2012. Protecting Disabled Children: Thematic Inspection.

Pollard, R., and S. Barnett. 2009. "Health-related vocabulary knowledge among deaf adults". Rehabilitation Psychology, 54(2): 182-185.

Sidebottom, P., M. Brandon, S. Bailey, P. Belderson, J. Dodsworth, J. Garstang, E., Harrison, A. Retzer, and P. Sorenson. 2016. Pathways to Harm, Pathways to Protection: A Triennial Analysis of Serious Case Reviews 2011 to 2014.

https://www.gov.uk/government/uploads/system/uploads/attachment_data/file/533826/Trienn ial Analysis of SCRs 2011-2014 - Pathways to harm and protection.pdf

Sutton-Spence, R. and B. Woll. 1999. The Linguistics of British Sign Language: An Introudction. Cambridge: Cambridge University Press.

Taylor, J., K.Stalker, and A. Stewart. 2015. "Disabled children and the child protection system: a cause for concern". Child Abuse Review, 25 (1): 60-73.

Valentine, G., and T. Skelton. 2007. "Re-Defining 'Norms': D/deaf Young People's Transitions to Independence." The Sociological Review 55(1): 104-123.

Young, A.M., R. Hunt, and C.Smith. 2008. The Impact of Integrated Children's Services on the Scope, Delivery and Quality of Social Care Services for Deaf Children and Families. London: NDCS. http://www.ndcs.org.uk/document.rm?id=3501

Young, A.M., R.Hunt, C.Smith and R Oram. 2010. The Impact of Integrated Children's Services on the Scope, Delivery and Quality of Social Care Services for Deaf Children and Families. Phase II Report. London: NDCS. http://www.ndcs.org.uk/document.rm?id=3501 Young, A.M., R. Hunt. 2011. NSSCR Methods Review 9: research with d/Deaf people. London: National School of Social Care Research. http://www2.lse.ac.uk/LSEHealthAndSocialCare/pdf/SSCR\%20Methods\%20Review 9 web. pdf 
Young, A.M., R. Hunt, and L. Stow. 2010. An Audit Framework to Assist Local

Safeguarding Children's Boards to Review the Execution of their Duties and Functions in Respect of Deaf Children.

http://www.ndcs.org.uk/search clicks.rm?id=5298\&destinationtype=2\&instanceid=414661

Young, A.M., and B. Temple. 2014. Approaches to Social Research: The Case of Deaf Studies. New York: Oxford University Press.

Young, A., R. Oram, C. Dodds, C. Nassimi-Green, R. Belk, K. Rogers, L. Davies and K Lovell. (2016). 'A qualitative exploration of trial-related terminology in a study involving Deaf British Sign Language users'. BMC Trials, 17: 219. doi: 10.1186/s13063-016-1349-6

\section{Funding Details}

This study was not supported by any direct research grant. However all authors and their organisations supported the initial conference from which the data are drawn and gave their time freely in the preparation of this article.

\section{Disclosure Statement}

No potential conflict of interest was reported by the authors.

\section{Author Biographies}

Shirley Wilson MRes, DipSW, CQSW is the Senior Consultant for d/Deaf and disabled children within the NSPCC with over 30 years local authority experience in child protection and management. Her Masters' research (2017) focused on disclosure of historical abuse with Deaf adults. She remains a registered social worker.

Michelle Attrill DipSW, DipHE was part of the leadership and management team for children and young people's sensory communication service in Suffolk and interim County Manager 
for the service until her departure in August 2017. She has worked in the fields of disability and sensory impairment for 20 years in Suffolk. She remains a registered social worker.

Joanne Hornsby, DipSW, BA Hons. is the interim lead for social care for children and young people for the sensory and communication service Suffolk County Council. She has been a social worker for 10 years in the field of sensory impairment and is a registered social worker with over 20 years' experience.

Tracey Critchley, DTLLS is the Co-ordinator of the Communication Support Unit for Deaf students at Harrow College, the largest specialist unit in West London.

Daniel Clements, BSc is a Senior Service Coordinator for RAD where he has worked for six years on service delivery projects linking with Children, Family and Transition Services, including guidance and advocacy support for young Deaf people. Prior to RAD he was involved in a range of different volunteering roles involving Deaf children and adults.

Christopher Mullen, BA Hons., CQSW, PGCCA, is the Social Care Policy Advisor within The National Deaf Children's Society since 2012. His role aims to raise awareness and influence others on the social care needs of deaf children. He has been a practitioner working with deaf children, families and deaf adults for nearly twenty years and remains a registered social worker.

David Miller is the Development and Impact Manager within the NSPCC. He has 18 years' experience in child protection and management, working in the field of child protection and services to disabled children and their families for many years. He has published reports and written guidance to raise the profile of the barriers to the effective safeguarding of disabled children.

Paul Redfern MA, CQSW is the Senior Community Development Manager for the BDA and safeguarding lead. He is also a qualified social worker. 
Timothy Richardson, (BA (Jt Hons), MA, DipSW), is the National Deaf CAMHS manager for the northern arm of the national service, he also manages a general CAMHS inpatient service. A qualified and registered social worker since 1999 and remains so. His work spans adults and children with learning disabilities, mental health issues including child and family assessment and support.

Lynn Stow, CQSW, PGDipSW has worked with d/Deaf people since 1989. She is the Team Manager for the Sensory Services Team (adults and children) in Kent. She collaborated on an audit framework to assist Local Safeguarding Boards (2010) in their work with deaf children and adults. She remains a registered social worker and is a Practice Educator and a member of the Practice Assessment Panel at Kent University.

Alys Young PhD, FAcSS, MA (Cantab.), MSC. (Oxon.), CQSW is Professor of Social Work at the University of Manchester, UK and visiting professor at the Centre for Deaf Studies, University of the Witwatersrand, Johannesburg, South Africa. She has worked in professional and academic roles alongside d/Deaf people for over 30 years. She remains a registered social worker. 